bureaucratic grip of the ministry and various political, financial, and individual interests. To continue the integration into the European higher education system, the academic community enhanced its contacts with international advisory bodies (Salzburg Seminar Universities Project, CRE Institutional Evaluation Program, Academia Europaea), whose experts visited Croatia in 2000. It was again recommended that university autonomy and management be strengthened.

Still, one cannot detect any political will in the government for such reforms. In fact, one notices some opposite tendencies. The draft of the new law envisions the possibility for the faculties to "leave" public universities; become "independent" faculties; by association, form new universities; or join other newly established (perhaps, even private) universities. This could lead to the privatization of large segments of the existing public higher education system. Coupled with the introduction of an unregulated free market in higher education (no quality control, no restrictions on enrollments, tuition fees, etc.) this could deprive most Croatian students of the opportunity to study, and ultimately even destroy the existing public higher education system.

In view of the crucial role that higher education plays in the development of a democratic and prosperous society, it becomes essential to study the origins and mechanisms of the resistance to the necessary reforms, from both the academic and political circles. Above all, this resistance needs to be eliminated, in Croatia as well as in other "transition" states of Central and Eastern Europe, before further irreparable damage is inflicted.

\title{
Higher Education Reform in Kyrgyzstan
}

\section{Thomas Wolanin}

Thomas Wolanin is a senior associate at the Institute for Higher Education Policy in Washington, DC. Address: Institute for Higher Education Policy, 1320 19th St., NW, Suite 400, Washington, DC 20036, USA. E-mail <tom@ihep.org>.

K yrgyzstan is a very mountainous, land-locked central Asian country with a population (4.8 million) and land area comparable to a medium-size U.S. state like Minnesota. It is a former republic of the Soviet Union that gained its independence in 1991. Since independence, Kyrgyzstan's GDP and per capita income have declined by more than 50 percent, and more than 60 percent of the population lives in poverty, including over 20 percent in severe poverty.

\section{Problems in Higher Education}

National poverty, the introduction of market capitalism, and the legacy of Soviet centralization have produced four severe problems in Kyrgyz higher education: corruption, a lack of connection between higher education and industry and student needs, redundancy in the higher education system, and low quality. First, corruption-it takes the form of either selling or providing, by the well-connected, of admission places, grades, and academic degrees as well as the theft of valuable resources, falsification of academic credentials, and the awarding of contracts in return for kickbacks. This corruption wastes scarce higher education resources and undermines the legitimacy of higher education. In this corrupt system the core academic value of recognizing and rewarding intellectual merit and achievement is ignored.

Second, higher education is not well linked to either the labor market or student demand. The system produces excess supplies of often poorly trained medical doctors and lawyers, while producing an insufficient number of much- needed accountants, financial managers, and teachers of computer science.

\section{National poverty, the introduction of mar- ket capitalism, and the legacy of Soviet centralization have produced four severe problems in Kyrgyz higher education.}

Third, because of the explosive growth in the number of institutions and levels of student enrollments, the higher education system suffers from extensive overlap and duplication. The number of higher education institutions has tripled from 33 to 114 , and the overall enrollment has grown from 65,000 to 159,000 students in the last five years. These levels are unsustainable given the country's expanding needs and insufficient resources.

Fourth, academic quality has significantly deteriorated as a result of the cumulative effects of corruption, low faculty salaries, an insufficient supply of appropriately trained faculty, shortages of textbooks and library and technology resources, and inadequate facilities. The proliferation of new and weak higher education institutions has exacerbated this problem.

\section{Reform Initiatives}

The new minister of education and culture, Camilla Sharshekeeva, who took office in early 2001, is launching a 
bold and comprehensive set of reform initiatives to address these problems. The first step is the identification of 8 of the 29 state higher education institutions to constitute a core higher education system to meet essential national economic, social, and political goals. These 8 institutions include 2 comprehensive universitiesone in the capital of Bishkek and one in Osh, the major city of the south-a technical university, a teacher training institution, an agricultural school, and three regional universities outside of the major urban areas. These institutions will be the focus of government reform efforts and support. Five major reforms are planned at these institutions. The reforms will be based upon the June report of the broad-based Working Group Examining the Rationalization and Funding of Higher Education in the Kyrgyz Republic.

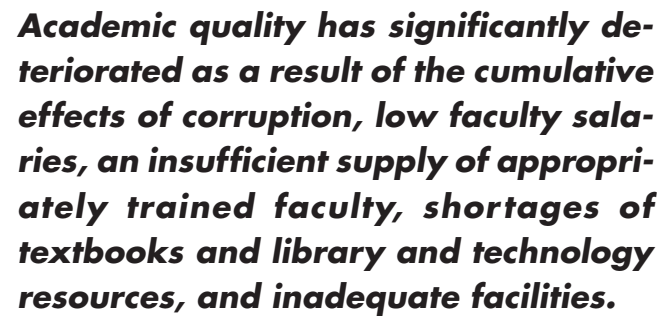

First, a lay board of trustees will assure the governance of each of these institutions. These boards, appointed by the minister of education and culture, will have as a first priority the restoration of financial and academic integrity, and it is expected that they will weed out ineffective administrators and faculty. The boards will be guided by specific mission statements that would, among other things, reflect labor market needs.

A second and closely related reform will be the introduction of generally accepted accounting principles and other measures for financial transparency and accountability. One important new element of this undertaking would be the annual production of consolidated and publicly available budgets showing all receipts and expenditures.

Third, control of the admissions process by individual institutions, a prime opportunity for corruption, would be replaced by admission on the basis of one or more examinations administered by a independent government testing agency. Special emphasis would be placed on security in the production and administration of the examinations.

Fourth, the current convoluted system of providing aid to exceptional students by paying the salaries of the faculty who teach them would be replaced by a national scholar- ship program. Performance on the admissions examination(s) would be used to determine national scholarship recipients, protecting these awards from corrupt influences. The student support system currently provides about 20 percent of the budget of state institutions of higher education. This is the largest source of government support for these institutions. With national scholarships allocating these funds based on the market choices of the scholarship recipients, the institutions that meet labor market demands and offer the greatest academic quality would receive the greatest benefits from this reform. In the long run national scholarship recipients could use their awards at any state or private institution without limitation, adding a market dynamic to the evolution of higher education.

Fifth, extremely low faculty salaries create economic pressures that lead to corruption and compromise academic quality. One goal of the new reforms is to raise average faculty salaries at the institutions in the core higher education system to the modest level of U.S.\$100 per month. Moderate tuition increases as well as possible support from the state budget or international donors will provide the resources for the subsidies needed to insure a wage floor for faculty.

\section{Long-Term Efforts}

These five initiatives are seen as the fundamental elements of real systemwide reform. In the longer term, other reforms will focus on the establishment of quality assurance mechanisms and on the reduction of the number of institutions. Ideally, the market will determine the number of state and private institutions, where the institutions at the core of the higher education system fare well as corruption-free institutions with high academic quality, clear missions, and enjoying broad political and financial support from the government.

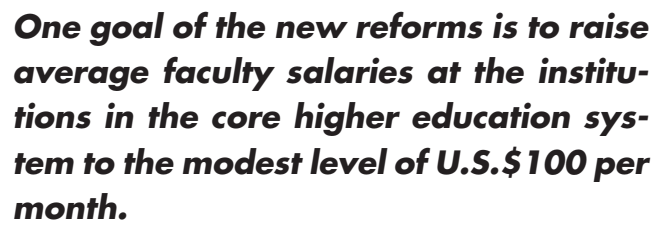

The vision is that this core system will embark on a legitimate cycle of improving quality, financial stability, financial and academic integrity, and effective service to the nation. If these reform initiatives are successfully implemented, Kyrgyz higher education could become a model of higher education reform for the other new nations of Central Asia. 